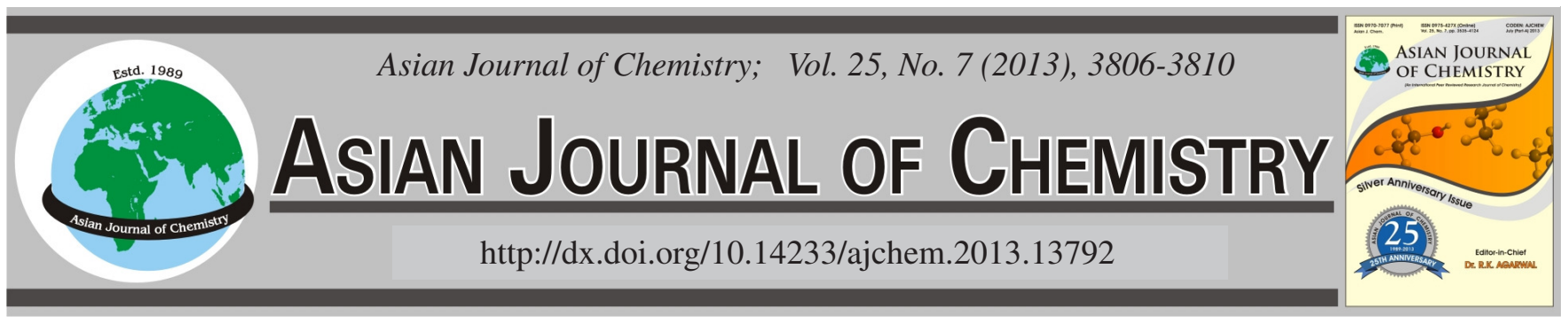

\title{
Synthesis and Micellization of Thermo/pH-Responsive Block Copolymer Poly(2-(diethylamino)ethylmethacrylate)-block-poly(N-isopropylacrylamide) Prepared via RAFT Polymerization
}

\author{
Chenglin Wu*, Anguo Ying, Shibin Ren and Jiankang Xu
}

School of Pharmaceutical and Chemical Engineering, Taizhou University, Taizhou 317000, Zhejiang Province, P.R. China

*Corresponding author: Fax: +86 576 85137182; Tel: +86 576 88667265; E-mail: clwu@tzc.edu.cn

\begin{abstract}
Double hydrophilic block copolymer, poly[2-(diethylamino)ethyl methacrylate]-block-poly(N-isopropylacrylamide), PDEAEMA-bPNIPAM, was successfully synthesized with good control via reversible addition fragmentation chain transfer radical polymerization (RAFT) with 4-cyanopentanoic acid dithiobenzoate (CPADB) as chain transfer agent in 1,4-dioxane. The diblock copolymer forms coreshell micelles in aqueous solution in dependence of $\mathrm{pH}$ and temperature. The behaviour of the double responsive block copolymer in solution was investigated by ${ }^{1} \mathrm{H}$ NMR and UV-visible. Cloud points measurements indicated that the the lower critical solution temperature (LCST) of poly $\left(\mathrm{N}\right.$-isopropylacrylamide) segment was decreased with increasing $\mathrm{pH}$ value of the solution, whereas the $\mathrm{pK}_{\mathrm{a}}$ value of PDEAEMA segment was about $\mathrm{pH} 7.5$.
\end{abstract}

Key Words: Stimuli-responsive polymers, Poly[2-(diethylamino)ethyl methacrylate], Poly(N-isopropylacrylamide), Block copolymer. ᄂ - - - - - - - - - - - - - - - - - - - - - - - - -

\section{INTRODUCTION}

Double hydrophilic block copolymers (DHBCs), which represent a class of copolymers with two or more water-soluble blocks made of different chemical species, have recently received the attention of many research groups due to switchable amphiphilic characteristics, the water solubility and the ability for controlled interactions with other nanosized building blocks ${ }^{1-5}$. Double hydrophilic block copolymers (DHBCs) often undergo physical or chemical transformations for one hydrophilic segment becomes hydrophobic, whereas another hydrophilic segment remains soluble in water. The transformation is often induced by subtle adjustment of the temperature, $\mathrm{pH}$, or ionic strength in solutions as well as complexation with appropriate molecules. Thus, double hydrophilic block copolymers provide a wide range of applications including biomimetic chemistry ${ }^{6}$, molecular switch ${ }^{7}$, drug carriers ${ }^{8}$ and gene delivery?

Poly(2-(diethylamino)ethyl methacrylate) (PDEAEMA), a weak polybase with a $\mathrm{pK}_{\mathrm{a}}$ of $c a \cdot 7.3^{10}$, is a $\mathrm{pH}$-responsive polymer. Above its $\mathrm{pK}_{\mathrm{a}}$, PDEAEMA is hydrophobic as its tertiary amine groups are deprotonated. Below its $\mathrm{pK}_{\mathrm{a}}$, PDEAEMA becomes a cationic hydrophilic polymer, as its tertiary amine groups are protonated. PDEAEMA can bind effectively with negatively charged DNA and thus is one of the desired components to be incorporated in the design of drug and gene delivery systems ${ }^{11}$. Poly(N-isopropylacryl amide) (PNIPAM), shows lower critical solution temperature (LCST) behaviour in aqueous solution, which is observed at $32{ }^{\circ} \mathrm{C}^{12}$. In addition, the LCST of PNIPAM-based polymers can be tuned via copolymerization with hydrophilic or hydrophobic polymers ${ }^{13,14}$. Thus, the PNIPAM containing copolymers have been prepared and self-assemble into thermo-responsive micelles as drug carriers.

In recent years, there has been considerable interesting on synthesizing the block copolymer contained pH-responsive segment and thermo-responsive segment by controlled/ living polymerization ${ }^{2,5,15}$. Muller et al. ${ }^{15}$ synthesized the $\mathrm{pH} /$ thermo double responsive block copolymer of poly(acrylic acid)-block-poly(N-isopropylacrylamide) via reversible addition fragmentation chain transfer polymerization (RAFT). Liu et al ${ }^{16}$ synthesized the $\mathrm{pH} /$ thermo-responsive diblock copolymer of PNIPAM-b-PDEAEMA via RAFT polymerization using 2-cyanoprop-2-yl dithiobenzoate (CDPB) as chain transfer agent and it was subsequently synthesized using the PNIPAM homopolymer as macro-CTA.

Herein, we report the synthesis of well-defined $\mathrm{pH} /$ thermo double responsive diblock copolymer of PDEAEMA-b- 
PNIPAM via RAFT polymerization using PDEAEMA as macro-CTA in 1,4-dioxane. The $\mathrm{pH} /$ thermo double responsive behaviour of the PDEAEMA-b-PNIPAM diblock copolymer in aqueous solution was studied by UV-visible and ${ }^{1} \mathrm{H}$ NMR spectra. These polymers might be applied in drug carriers and gene delivery and biotechnology.

\section{EXPERIMENTAL}

2-(Diethylamino) ethyl methylacrylate (DEAEMA) (Aldrich, $99 \%$ ) was purified by passing through a basic alumina column and distilling from $\mathrm{CaH}_{2}$ under reduced pressure. N-Isopropylacrylamide (NIPAM) (Aldrich, $97 \%$ ) was purified by recrystallization from a mixture of benzene and hexane (3/ 7, v/v) before use. 4, 4'-Azobis(4-cyanopentanoic acid) (ACPA) (Acros, $97 \%$ ) was dried under vacuum prior to use. 4-Cyanopentanic acid dithiobenzoate (CPADB) was synthesized according to the methods reported in the literature ${ }^{17}$. All solvents were redistilled before use. Other reagents were used as received.

Synthesis of PDEAEMA homopolymer: DEAEMA (0.92 g, $4.97 \mathrm{mmol})$, ACPA (5.8 mg, $0.021 \mathrm{mmol})$ and CPADB (46.3 $\mathrm{mg}, 0.17 \mathrm{mmol})$ were dissolved in 1,4-dioxane $(4 \mathrm{~mL})$ in a flask. The solution was degassed by three freeze-vacuumthaw cycles. The polymerization was carried out at $70{ }^{\circ} \mathrm{C}$ for $24 \mathrm{~h}$ and stopped by cooling the solution in ice water. The polymer solution was poured into a large excess of $n$-hexane to precipitate PDEAEMA homopolymer. The viscous polymer was dried under vacuum to constant weight. The obtained polymer ( $0.38 \mathrm{~g}, 40.8 \%$ conversion) could be used as a macro-CTA.

Synthesis of PDEAEMA-b-PNIPAM block copolymer: PDEAEMA (0.146 g, $\left.3.84 \times 10^{-2} \mathrm{mmol}\right)$, NIPAM (0.317 g, $2.81 \mathrm{mmol})$ and ACPA $\left(2.8 \mathrm{mg}, 1.0 \times 10^{-2} \mathrm{mmol}\right)$ were dissolved in 1,4-dioxane in a flask. The solution was degassed by three freeze-vacuum-thaw cycles. The block copolymerization was carried out at $70^{\circ} \mathrm{C}$ for $48 \mathrm{~h}$ and stopped by cooling the solution in ice water. The block copolymer was purified by dialysis against distilled water for a week, changing the water twice a day (MWCO 7,000) and recovered by a freeze-drying technique. The results of the homopolymer and diblock copolymer listed in Table-1.

\section{TABLE-1}

CHARACTERISTICS OF PDEAEMA HOMOPOLYMER AND PDEAEMA-b-PNIPAM DIBLOCK COPOLYMER

\begin{tabular}{lccccc}
\hline \multicolumn{1}{c}{ Samples } & Conversion & $\mathrm{M}_{\mathrm{n}}{ }^{\mathrm{a}}$ & $\mathrm{M}_{\mathrm{n}}{ }^{\mathrm{b}}$ & $\mathrm{M}_{\mathrm{w}}{ }^{\mathrm{b}}$ & PDI $^{\mathrm{b}}$ \\
\hline PDEAEMA & 40.8 & 7.3 & 3.8 & 4.3 & 1.12 \\
PDEAEMA- & 43.2 & 20.9 & 11.5 & 14.3 & 1.24 \\
b-PNIPAM & \multicolumn{7}{l}{} \\
\hline
\end{tabular}

Per cent transmittance: The transmittance of aqueous solution of polymer was determined at $\lambda=600 \mathrm{~nm}$ by Shimadzu UV-2101PC UV-visible spectrophotometer equipped with a Julabo F12 temperature control unit. The LCST of diblock copolymer was defined as the temperature inducing a $10 \%$ decreasing in optical transmittance. The polymeric concentration was kept at $0.2 \mathrm{wt} \%$ in all cases.

Potentiometric titration: The titration was performed under constant stirring at $25^{\circ} \mathrm{C}$ of $0.2 \mathrm{wt} \%$ polymeric solution.
The concentration of $\mathrm{HCl}$ was $4.65 \times 10^{-3} \mathrm{M}$ used in the experiment.

Detection method: ${ }^{1} \mathrm{H}$ NMR measurements were performed on a Varian UNITY-plus 400M nuclear magnetic resonance spectrometer using $\mathrm{CDCl}_{3}$ and $\mathrm{D}_{2} \mathrm{O}$ as the solvents, respectively. The number-average molecular weight $\left(M_{n}\right)$ and weight-average molecular weight $\left(\mathrm{M}_{\mathrm{w}}\right)$ and polydispersity $\left(\mathrm{M}_{\mathrm{w}} / \mathrm{M}_{\mathrm{n}}\right)$ of the polymers were estimated by gel permeation chromatograph (GPC) at $35^{\circ} \mathrm{C}$ with a Waters 1525 chromatograph equipped with a Waters 2414 refractive index detector. THF was used as the mobile phase at a flow rate of $1 \mathrm{~mL} / \mathrm{min}$. Polystyrene standard was employed for calibration.

\section{RESULTS AND DISCUSSION}

Synthesis of the PDEAEMA-b-PNIPAM block copolymer: PDEAEMA-b-PNIPAM was synthesized via RAFT polymerization. with PDEAEMA as chain transfer agent. The obtained polydispersity is very low. Table- 1 summarizes the results of the homopolymer and diblock copolymer.

Fig. 1A exhibits a time-conversion relationship along with the pseudo-first-order kinetic plot for the polymerization of NIPAM in the presence of PDEAEMA macro-CTA and ACPA at $70^{\circ} \mathrm{C}$ under $\mathrm{N}_{2}$ atmosphere in 1,4-dioxane, where the monomer/CTA/initiator ([NIPAM $\left.]_{0} /[\text { PDEAEMA }]_{0} /[\text { ACPA }]_{0}\right)$ molar ratio is $520 / 4 / 1$. The polymerization mixture was subjected to NMR measurements as a function of polymerization to obtain the time-conversion curve. The NIPAM conversion was determined from the ratio between the area of vinyl proton peak at $6.1 \mathrm{ppm}$ and that of the methine proton at $3.9 \mathrm{ppm}$. Values of $\mathrm{M}_{\mathrm{n}}$ and PDI $\left(\mathrm{M}_{\mathrm{w}} / \mathrm{M}_{\mathrm{n}}\right)$ for PDEAEMA macro-CTA used were predetermined to be $3.8 \times 10^{3}$ between the area of the end benzene protons at 7.4-8.0 ppm and that of the methylene protons at $4.0 \mathrm{ppm}$ and 1.12 , respectively. The pseudo-firstorder kinetic plot was consistent with a "living" polymerization mechanism over the $28 \mathrm{~h}$; the concentration of active propagating radical species remains nearly constant during this part of the polymerization. Beyond $28 \mathrm{~h}$, downward curvature was observed, which may indicate a decrease in the concentration of propagating radicals. As shown in Fig. 1B, the GPC traces of PDEAEMA-b-PNIPAM taken at increasing reaction time showed a continuous shift to higher molecular weight. The GPC elution profiles were unimodal, which indicated that no lower molecular weight PNIPAM homopolymer newly formed. Fig. $1 C$ shows the evolution of $M_{n}$ and PDI for the polymers obtained by RAFT polymerization of NIPAM as a function of the NIPAM monomer conversion. The Mn and polydispersity and monomer conversion were estimated from GPC and ${ }^{1} \mathrm{H}$ NMR, respectively. The evolution of $M_{n}$ with conversion was found to be linear over the $28 \mathrm{~h}$ and therefore indicated a controlled polymerization. The PDI increased slightly with the conversion but remained in the range of 1.1-1.3. These observations indicated that the polymerization is reasonably well controlled as "living" in nature.

Thermo-responsive of the PDEAEMA-b-PNIPAM diblock copolymer: The thermo-responsive DHBCs contained PNIPAM segment could be investigated by ${ }^{1} \mathrm{H}$ NMR, for the protons of the micellar core could not observed in the ${ }^{1} \mathrm{H}$ NMR spectrum and the protons of the shell remained visible both 

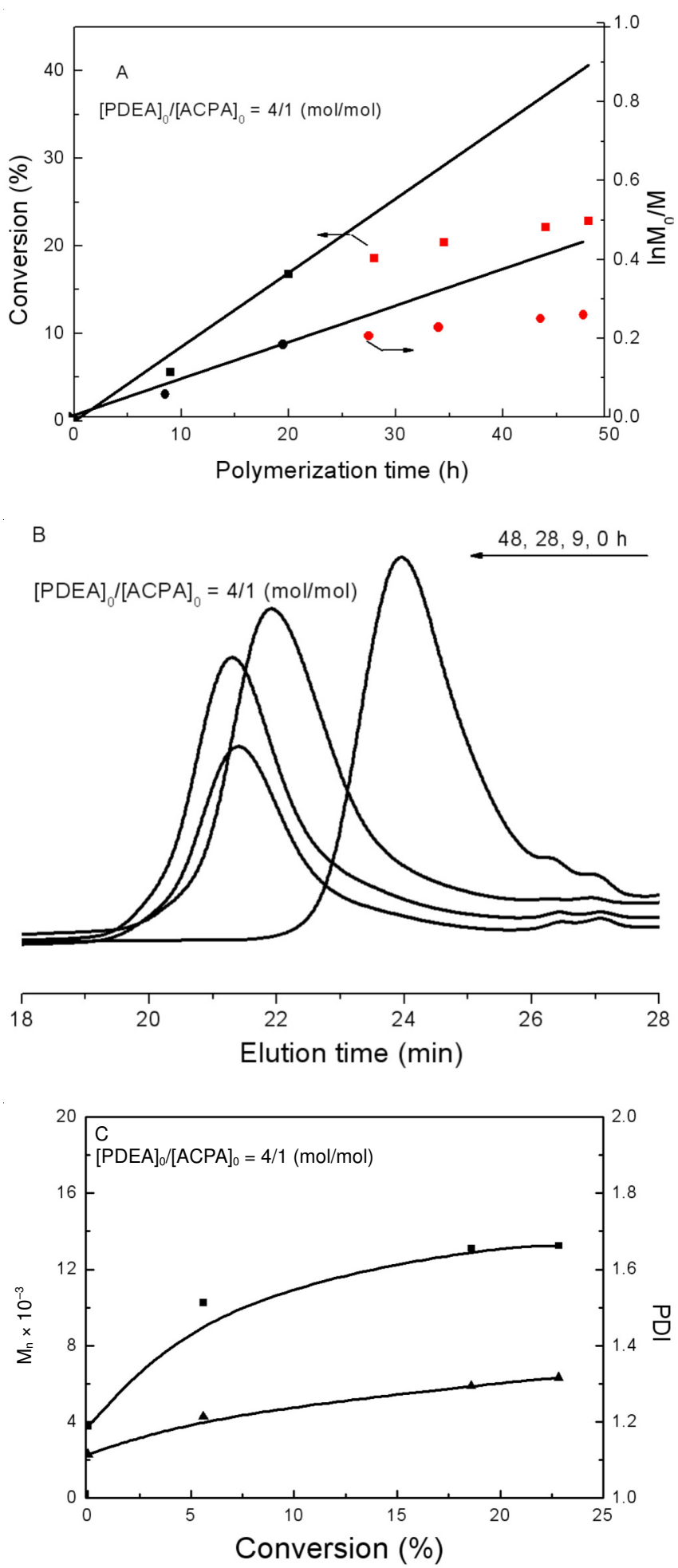

Fig. 1. (A) Conversion-time (squares) and the pseudo-first-order kinetic plots (circles) for the polymerization of NIPAM with ACPA in the presence of PDEAEMA in 1,4-dioxane at $70{ }^{\circ} \mathrm{C}$ using a $[\mathrm{PDEAEMA}]_{0} /[\mathrm{ACPA}]_{0}$ molar ratio of $4 / 1$. (B) GPC traces of PDEAEMA-b-PNIPAM samples taken at different polymerization time. (C) Number average molecular weight (squares) and polydispersity $\left(\mathrm{M}_{\mathrm{w}} / \mathrm{M}_{\mathrm{n}}\right)$ (triangles) of PDEAEMA-b-PNIPAM as a function of conversion at $70{ }^{\circ} \mathrm{C}$

before and after micellization ${ }^{18}$. Heat-induced association of PDEAEMA-b-PNIPAM was observed in ${ }^{1} \mathrm{H}$ NMR spectra measured at different temperatures in $\mathrm{D}_{2} \mathrm{O}$. Fig. 2 shows the ${ }^{1} \mathrm{H}$ NMR spectra of PDEAEMA-b-PNIPAM measured at $\mathrm{pH}$

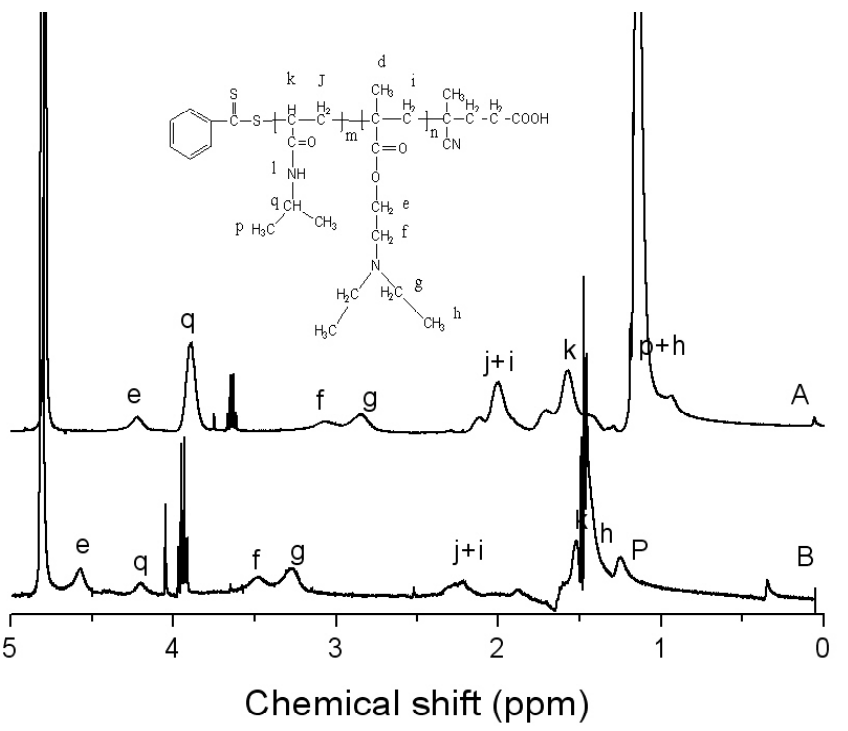

Fig. 2. $\quad{ }^{1} \mathrm{H}$ NMR spectra of PDEAEMA-b-PNIPAM in $\mathrm{D}_{2} \mathrm{O}$ at $\mathrm{pH} 3.0$ under $25^{\circ} \mathrm{C}(\mathrm{A})$ and $50{ }^{\circ} \mathrm{C}(\mathrm{B})$

3.0 under $25^{\circ} \mathrm{C}(\mathrm{A})$ and $50^{\circ} \mathrm{C}(\mathrm{B})$. The resonance peaks in the $2.8 \mathrm{ppm}(\mathrm{g}), 3.1 \mathrm{ppm}$ (f) and $4.2 \mathrm{ppm}(\mathrm{e})$, observed at $25^{\circ} \mathrm{C}$, were attributed to the side-chain methylene protons in the PDEAEMA unit. The resonance peaks at $3.9 \mathrm{ppm}$ (q) was attributed to the methine protons in the pendent isopropyl group in the NIPAM unit. The composition of PDEAEMA-b-PNIPAM was calculated from the intensity ratio of the resonance bands due to the methylene protons in the side chain of the DEAEMA unit at $4.2 \mathrm{ppm}$ (e) and the methine protons in the side chain of NIPAM unit at $3.9 \mathrm{ppm}$ (e) at $25^{\circ} \mathrm{C}$. The PDEAEMA-bPNIPAM protons resonance peaks shift to higher fields at elevated temperatures. It is an important observation that the intensities of the resonance peaks due to the isopropyl protons in the NIPAM unit ( $q$ and $p$ ) relative to the intensity of the resonance peak of due to the side methylene protons in the DEAEMA unit (e) are considerably lower at $50^{\circ} \mathrm{C}$ than $25^{\circ} \mathrm{C}$.

The diblock copolymer is completely soluble in aqueous solution at $25^{\circ} \mathrm{C}$. The transmittance of the buffer aqueous solutions (0.05 M phosphate buffer solution with $\mathrm{pH} 7.4$ and citrate buffer with $\mathrm{pH}$ 3.0) of PDEAEMA-b-PNIPAM (0.2 wt $\%$ ) was determined at various temperatures by UV-Vis spectrophotometer at a wavelength of $600 \mathrm{~nm}$ (Fig. 3). At pH 3.0, the measured LCST is about $37^{\circ} \mathrm{C}$, which is higher than LCST of pure PNIPAM homopolymer ${ }^{12}$. The shift of LCST to higher temperature is attributed to the hydrophilic PDEAEMA segments at $\mathrm{pH}$ 3. At pH 7.4 (blood normal pH), the LCST value decreases to $c a .33^{\circ} \mathrm{C}$. It is apparent that the LCST values decrease with increasing the $\mathrm{pH}$ values. Turbid solutions above LCST become clear again when the solutions are cooled below the LCST of PNIPAM.

pH-Responsive of the PDEAEMA-b-PNIPAM diblock copolymer: The degree of neutralization $(\alpha)$ of the amine group of DEAEMA is defined as

$$
\alpha=\frac{\left([\text { Acid }]-\left[\mathrm{H}^{+}\right]+\left[\mathrm{OH}^{-}\right]\right.}{[\text {Amine }]}
$$

where [acid], $\left[\mathrm{H}^{+}\right]$and $\left[\mathrm{OH}^{-}\right]$are the concentrations of added acid, free $\mathrm{H}^{+}$and $\mathrm{OH}^{-}$, respectively and [amine] is the total 


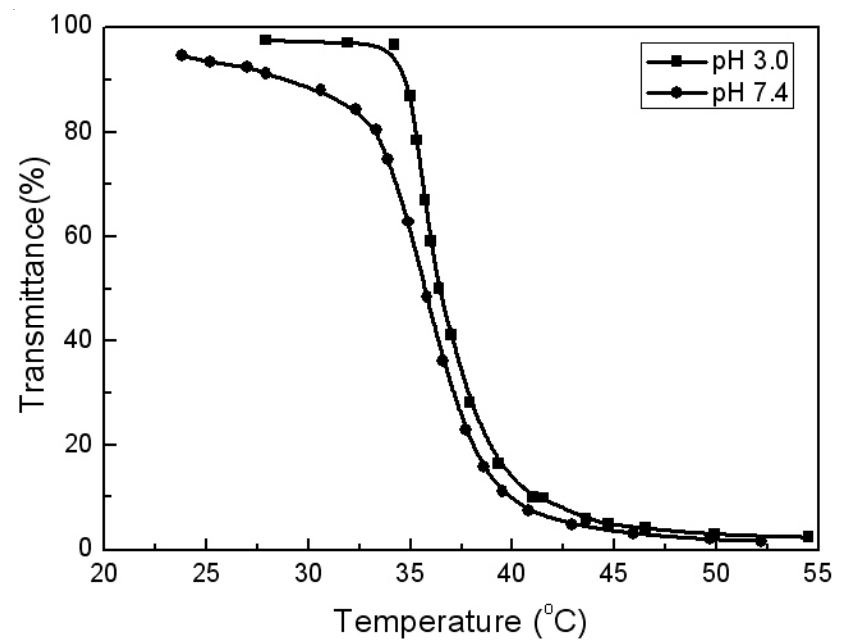

Fig. 3. Temperature dependence of transmittance of the buffer aqueous solutions of PDEAEMA-b-PNIPAM $(0.2 \%)$ at $\mathrm{pH} 3.0$ (square) and $\mathrm{pH} 7.4$ (circle)

concentration of amine groups. The negative logarithm dissociation constant $\left(\mathrm{pK}_{\mathrm{b}}\right)$, which provides additional information on the polymer morphology at various $\mathrm{pH}$ conditions, can be described by the Henderson-Hasselbalch equation:

$$
\mathrm{pK}_{\mathrm{b}}=14-\mathrm{pH}+\log \left(\frac{(1-\alpha)}{\alpha}\right)
$$

Fig. 4 shows the $\mathrm{pH}$ and $\mathrm{pK}_{\mathrm{b}}$ curves of the PDEAEMA-bPNIPAM block copolymer solution $(0.2 \mathrm{wt} \%)$ as a function of $\alpha$. As shown in Fig. 4A, the $\mathrm{pH}$ value decreased with increasing $\alpha$ and it exhibited a plateau for $0.15<\alpha<0.40$. The conformational transitions were also demonstrated by the change in the slope of the $\mathrm{pK}_{\mathrm{b}}$ profile (Fig. 4B). The negative logarithm of the intrinsic dissociation constant $\left(\mathrm{pK}_{0}\right)$ could be determined by extrapolating the $\mathrm{pK}_{\mathrm{b}}$ curve to $\alpha=0$ and the $\mathrm{pK}_{0}$ value for the polymer solution $(0.2 \mathrm{wt} \%)$ is $c a .8 .2$, as was reported by Tam et al. ${ }^{19}$. The $\mathrm{pK}_{\mathrm{b}}$ curve can be divided into three regions. The slope in the $\mathrm{pK}_{\mathrm{b}}$ curve $(\alpha<0.15)$ is negative, which indicates that the amine groups of PDEAEMA are favorable protonation and the PDEAEMA segments are hydrophobic. As a increases $(0.15<\alpha<0.40)$, the PDEAEMA chains become protonated and the chain conformation becomes more extended.

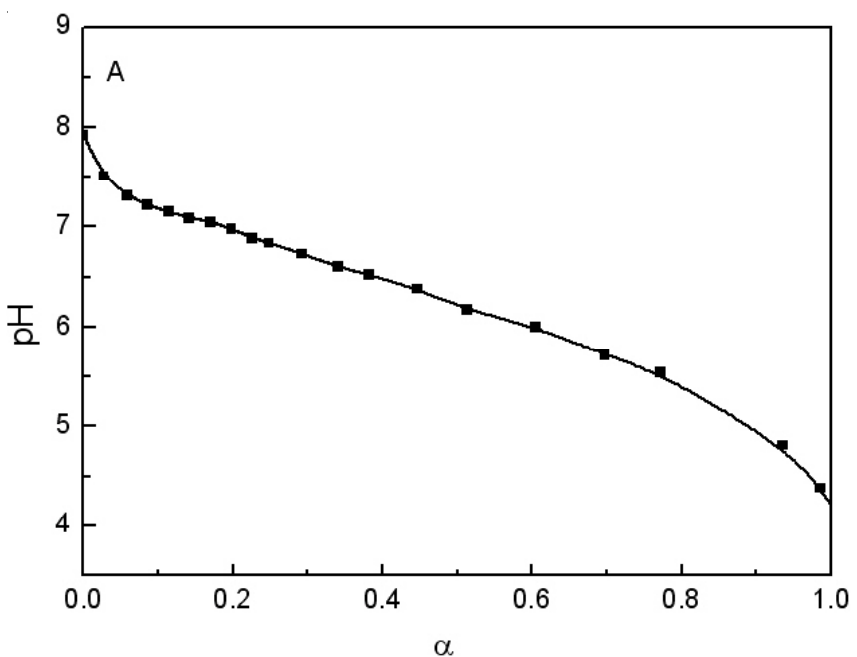

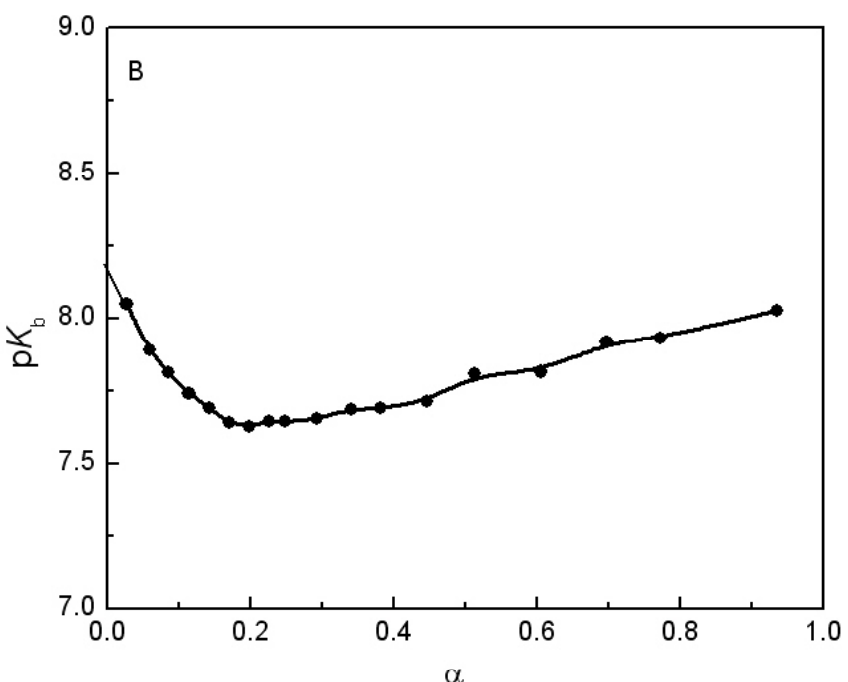

Fig. 4. Titration curves of (A) $\mathrm{pH}$ and (B) $\mathrm{pK}_{\mathrm{b}}$ for the polymer solution $(0.2$ wt \%)

$\mathrm{pH}$-Induced association of PDEAEMA-b-PNIPAM was also observed in ${ }^{1} \mathrm{H}$ NMR spectra, for the protons of the micellar core could not observed in the ${ }^{1} \mathrm{H}$ NMR spectrum and the protons of the shell remained visible both before and after micellization ${ }^{20}$. Fig. 5 shows the ${ }^{1} \mathrm{H}$ NMR spectra of PDEAEMA-b-PNIPAM measured at pH 3.0 (A), pH 7.4 (B) and $\mathrm{pH} 11.0(\mathrm{C})$ under $25^{\circ} \mathrm{C}$. The gradual shift of the peaks at 3.3-3.4, 3.6 and 4.4-4.5 ppm corresponding to the protons of the PDEAMEA side groups to lower area was clearly observed due to the less effective shielding of the electron pair of the deprotonated nitrogen at $\mathrm{pH} 3$ and the resonance peaks of PDEAEMA were almost disappearance at $\mathrm{pH} 11$ due to the forming micellar core of the deprotonated PDEAEMA segment and micellar shell of the hydrophilic PNIPAM segment.

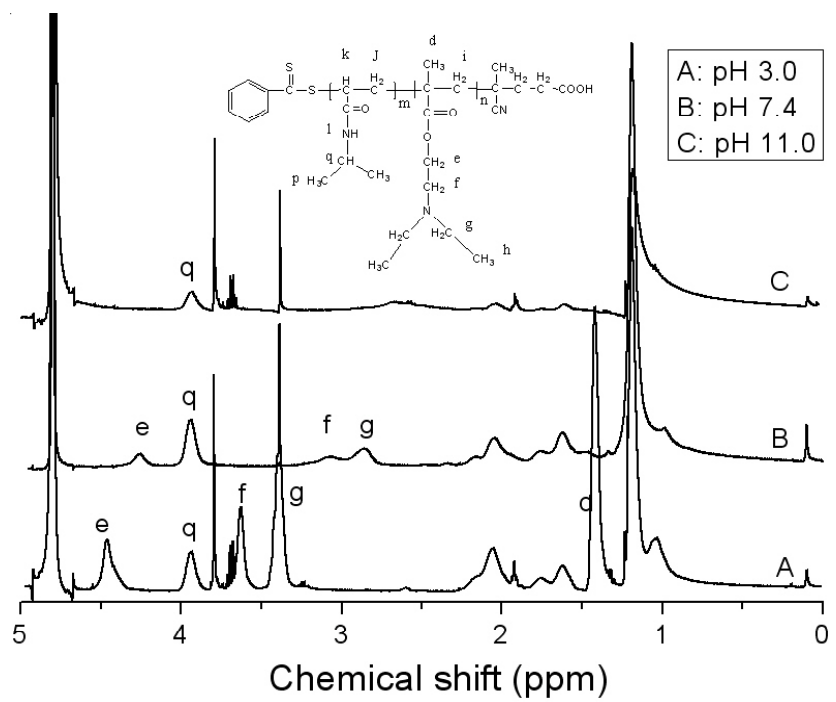

Fig. 5. ${ }^{1} \mathrm{H}$ NMR spectra of PDEAEMA-b-PNIPAM in $\mathrm{D}_{2} \mathrm{O}$ at $25^{\circ} \mathrm{C}$ under pH 3.0 (A), pH 7.4 (B) and pH 11.0 (C)

To further determine the $\mathrm{pH}$-responsive behaviour of the PDEAEMA-b-PNIPAM diblock copolymer, the transmittance of the polymer solution $(0.2 \mathrm{wt} \%)$ with various $\mathrm{pH}$ values was determined by UV-Vis spectrophotometer at a wavelength of $600 \mathrm{~nm}$ (Fig. 6). The transmittance of the solution was 


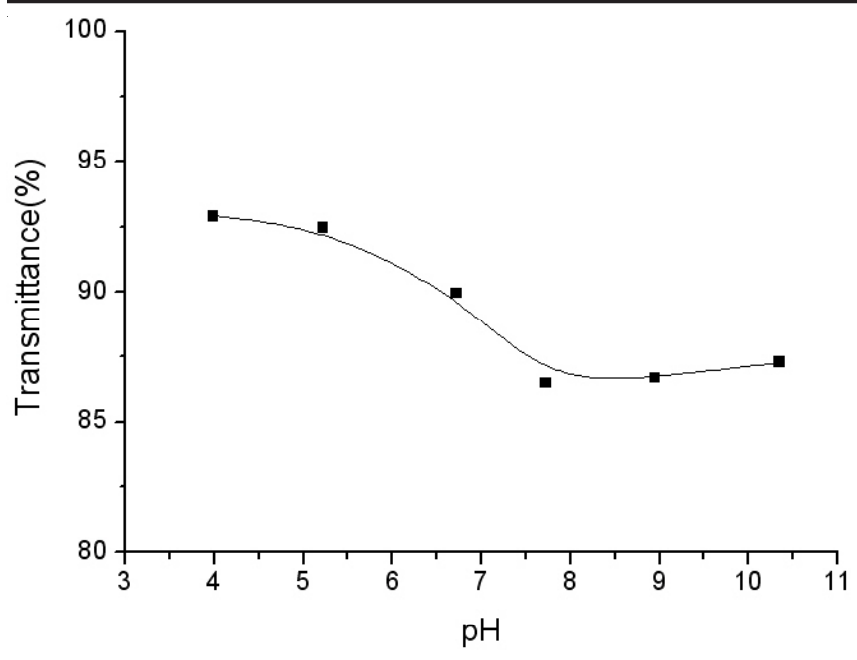

Fig. 6. $\mathrm{pH}$ dependence of transmittance of the PDEAEMA-b-PNIPAM solution $(0.2$ wt $\%)$ at $25^{\circ} \mathrm{C}$

decreased with increasing the $\mathrm{pH}$ value and it exhibited a plateau for $\mathrm{pH}>7.5$ due to forming stable core-shell structure with the PDEAEMA block as the core and the PNIPAM block as the shell.

\section{Conclusion}

Well-defined PDEAEMA-b-PNIPAM diblock copolymer was successfully synthesized with good control via RAFT polymerization with macro-CTA PDEAEMA as chain transfer agent in 1,4-dioxane. The block copolymer forms core-shell micelles in aqueous solution in dependence on $\mathrm{pH}$ and temperature. Cloud points measurements indicated that the LCST of PNIPAM segment was decreased with increasing $\mathrm{pH}$ value of the solution, whereas the $\mathrm{pK}_{\mathrm{a}}$ value of PDEAEMA segment was ca. $\mathrm{pH} 7.5$.

\section{ACKNOWLEDGEMENTS}

The authors thank the National Natural Science Foundation of China (No. 21106090) and China Postdoctoral Science Foundation (2011M500990) for financial support.

\section{REFERENCES}

1. G. Mountrichas and S. Pispas, Macromolecules, 39, 4767 (2006).

2. Z. Ge, D. Xie, D. Chen, X. Jiang, Y. Zhang, H. Liu and S. Liu, Macromolecules, 40, 3538 (2007).

3. C. Luo, Y. Liu and Z. Li, Macromolecules, 43, 8101 (2010).

4. M.A.C. Stuart, W.T.S. Huck, J. Genzer, M. Muller, C. Ober, M. Stamm, G.B. Sukhorukov, I. Szleifer, V.V. Tsukruk, M. Urban, F. Winnik, S. Zauscher, I. Luzinov and S. Minko, Nature Mater., 9, 101 (2010).

5. X. Liu, P. Ni, J. He and M. Zhang, Macromolecules, 43, 4771 (2010).

6. S. Yu, H. Cölfen, J. Hartmann and M. Antonietti, Adv. Funct. Mater., 12, 541 (2002).

7. T. Shimoboji, E. Larenas, T. Fowler, A.S. Hoffman and P.S. Stayton, Bioconjug. Chem., 14, 517 (2003).

8. N. Karanikolopoulos, M. Pitsikalis, N. Hadjichristidis, K. Georgikopoulou, T. Calogeropoulou and J.R. Dunlap, Langmuir, 23, 4214 (2007).

9. N.M. Moore, C.L. Sheppard and S.E. Sakiyama-Elbert, Acta Biomater., 5, 854 (2009)

10. S. Liu, J.V.M. Weaver, M. Save and S.P. Armes, Langmuir, 18, 8350 (2002).

11. J.F. Tan, H.P. Too, T.A. Hatton and K.C. Tam, Langmuir, 22, 3744 (2006).

12. H.G. Schild, Prog. Polym. Sci., 17, 163 (1992).

13. R. Nojima, T. Sato, X.P. Qiu and F.M. Winnik, Macromolecules, 41, 292 (2008)

14. P. Kujawa, F. Tanaka and F.M. Winnik, Macromolecules, 39, 3048 (2006).

15. C.M. Schilli, M. Zhang, E. Rizzardo, S.H. Zhang, Y.K. Chong, K. Edwards, G. Karlsson and A.H.E. Mulller, Macromolecules, 37, 7861 (2004).

16. Z. Ge, Y. Cai, J. Yin, Z. Zhu, J. Rao and S. Liu, Langmuir, 23, 1114 (2007).

17. S.H. Zhang, Y.K. Chong, R.T.A. Mayadunne, G. Moad and E. Rizzardo, Tetrahedron Lett., 40, 2435 (1999).

18. S.I. Yusa, Y. Shimada, Y. Misukami, T. Yamamoto and Y. Morishima, Macromolecules, 37, 7507 (2004).

19. J.F. Tan, P. Ravi, H.P. Too, T.A. Hattton and K.C. Tam, Biomacromolecules, 6, 498 (2005).

20. M. Vamvakaki, D. Palioura, A. Spyros, S.P. Armes and S.H. Anastasiadis, Macromolecules, 39, 5106 (2006) 